\title{
EFFECT OF PROCESS CONTROL AND POWDER QUALITY ON INCONEL 718 PRODUCED USING ELECTRON BEAM MELTING
}

\author{
W.J. Sames ${ }^{1,2}$, F. Medina ${ }^{3}$, W.H. Peter ${ }^{2,4}$, S.S. Babu ${ }^{2,5}$, and R.R. Dehoff ${ }^{2,4}$ \\ ${ }^{1}$ Department of Nuclear Engineering, Texas A\&M University, College Station, TX; \\ ${ }^{2}$ Manufacturing Demonstration Facility, Oak Ridge National Laboratory, Knoxville, TN; \\ ${ }^{3}$ Arcam AB, Sweden; \\ ${ }^{4}$ Materials Science and Technology Division, Oak Ridge National Laboratory, Oak Ridge, TN; \\ ${ }^{5}$ Department of Aerospace and Biomedical Engineering, University of Tennessee, Knoxville, TN
}

Keywords: additive manufacturing, powder quality, mechanical testing

\begin{abstract}
Powder bed additive manufacturing technologies have the potential to fabricate complex metal components with increased performance at lower costs than conventional processes. The Arcam Electron Beam Melting (EBM) process distributes metal powder in thin layers $(50-200 \mu \mathrm{m})$ which are melted by a focused electron beam at specific locations specified by a computer file. Work is presented that demonstrates the ability to fabricate Inconel 718 components from powder and discusses challenges with reference to process control and final properties. Processing defects may be avoided by changing the power/velocity relationship and powder bed temperature. Powder quality also plays an important role in additive manufacturing metallurgy, and the effect on EBM parts is explored. The importance of the hold time and hold temperature of the part during fabrication greatly affect tensile properties in the results presented. The relationship between processing parameters, powder quality, and mechanical properties is discussed.
\end{abstract}

\section{Background}

Additive manufacturing (AM) builds material up, layer by layer. Metal AM processes typically use a laser or an electron beam as a heat source to melt metal powder. Laser based techniques are generally performed near room temperature and experience rapid solidification as a result. Much work has been done on laser based Inconel 718 material production and characterization, using both Powder Bed Fusion and Direct Energy Deposition. Microstructure has been characterized [1], mechanical tests and fractography have been performed [2] [3], and densification has been analyzed [4] [5]. Tensile and hardness tests are the most commonly tested mechanical properties and are best reported in as-fabricated condition, alongside data for heat treated material.

Less work exists on Electron Beam Melting (EBM) of Inconel 718, as EBM has historically focused on titanium alloys. Initial work on Inconel 718 was performed by Stondl et al. to characterize the precipitates formed [6], grain orientation, tensile properties, and fracture behavior [7]. Hardening mechanisms have also been discussed [8]. The details of the EBM 
process are crucial to understanding the microstructure and mechanical properties of the material, and are explored in more depth in this manuscript.

While conventional processes are well characterized for microstructure and mechanical properties, the relative complexity and the fast pace of machine improvement of AM technologies limits the extent of classification that has been performed on the material. In addition, AM produced material needs to be qualified over a range of geometries, so that the quality of parts can be assured. However, this manuscript focuses on the material properties as a result of process parameters and material feedstock of simple geometric shapes. Additional characterization will be required with increased component complexity in order to understand microstructure and property changes with shape.

\section{Procedures}

An Arcam A2 EBM machine was used to produce the Inconel 718 material discussed in this paper. This machine is capable of a focused beam diameter down to $200[\mu \mathrm{m}]$, an accelerating voltage of $60[\mathrm{kV}]$, layer thickness of $50-200[\mu \mathrm{m}]$, and build temperatures up to $1100^{\circ} \mathrm{C}$ as measured under the substrate. The beam speed used ranges up to $10[\mathrm{~m} / \mathrm{s}]$. The melt current varies from 2-50[mA]. Two versions of the process control software were used: version 3.2 and version 4.1. Version 4.1 utilizes more complex scan strategies, including more complex rotation angles (3.2 only used right angles). For each layer of material deposited, there are various distinct process steps utilized. The EBM process must achieve a proper powder bed temperature to avoid over-excitation of the particles and large-scale removal of the particles from the powder bed, in a phenomenon known as "smoking". Preheat and post-heat processes use a more diffuse electron beam as a heat source and are applied to control the temperature of the powder bed. A thermocouple was used to measure the temperature range and was between $900^{\circ} \mathrm{C}$ and $1100^{\circ} \mathrm{C}$ during the melt process for this work. As the temperature of a new powder layer is raised by preheat, the powder is sintered. The electron beam is then focused and scanned to melt the powder. A post heat of the layer is performed in a similar manner to the preheat to maintain build volume temperature. The EBM process uses two distinctly different melt profiles: contours and hatch. The contours melt a perimeter around the surface of the part by applying the beam in a series of discrete spots around the edge of the part slice. The hatch then fills in the bulk of the part using a snaking beam path. A range of Inconel powders were evaluated including gas atomized (GA), rotary atomized (RA), and plasma rotated electrode process (PREP) powders with approximate size range distributions as provided in Table 1. Powders were characterized using a Hitachi S-4800 FEG-SEM. Samples were cold mounted and polished to a 1 micron diamond finish. Electro-etching was done using a $70 \mathrm{~mL}$ phosphoric acid and $30 \mathrm{~mL}$ distilled water solution, applying $2 \mathrm{~V}$ for 15 seconds. Electro-etching was required to fully reveal grain boundaries, as other etchants (like Glyceregia) did not work. 
Table 1. Particle size analysis; All values in \% by mass, and sieve analysis was performed to ASTM Standard B214-07, but using 1 [kg] of powder instead of $100[\mathrm{~g}]$.

\begin{tabular}{|l|l|l|l|l|l|}
\hline $\begin{array}{l}\text { Particle } \\
\text { Size } \\
\text { [micron] }\end{array}$ & $>250$ & $\begin{array}{l}\leq 250 \\
150\end{array}$ & $\leq 150>75$ & $\leq 75>45$ & $\leq 45$ \\
\hline $\begin{array}{l}\text { Sieve } \\
\text { Number }\end{array}$ & +60 & $-60 /+100$ & $-100 /+200$ & $-200 /+325$ & -325 \\
\hline Method & & & & & \\
\hline GA & $0.00 \%$ & $0.02 \%$ & $99.58 \%$ & $0.26 \%$ & $0.14 \%$ \\
\hline RA & $0.00 \%$ & $0.13 \%$ & $66.21 \%$ & $33.14 \%$ & $0.52 \%$ \\
\hline PREP & $0.00 \%$ & $0.01 \%$ & $54.93 \%$ & $44.38 \%$ & $0.68 \%$ \\
\hline
\end{tabular}

All builds discussed in this paper were made on top of a stainless steel substrate. Inconel 718 adheres to the substrate, which is good for mechanical stability while building the part. However, the difference in thermal expansion coefficients and high temperatures of the build envelope can lead to issues with warping, with plate deflection typically $<5 \mathrm{~mm}$. Adherence to the substrate also means that parts must be cut or machined off. This is similar to other AM processes, which use substrate of the same material as the build. Further work is required to develop a better substrate for the Inconel 718 EBM process, to reduce substrate warping and allow parts to be removed from the substrate by hand.

The Standard ASTM E8/E8M for round specimens was considered, within geometrical guidelines for small samples. [9] The gauge diameter was $2.54 \mathrm{~mm}(0.1 \mathrm{in})$ and the grip diameter was $7.62 \mathrm{~mm}(0.3 \mathrm{in})$, with total length up to $80 \mathrm{~mm}$ (3.15in) depending on material constraints to accommodate space for an extensometer. Some small lathe marks were noted on the samples after failure, which could have influenced results. Reported values of elongation are taken from global strain measurement, without accounting for change in cross section at the end of the gauge length. This means that the elongation values reported are conservative estimates and maybe systematically underreported.

Gradients in grain size in the build direction have been demonstrated in Ti-6Al-4V produced by EBM. [10] Other work has shown variance in precipitate coarsening in the build direction in Inconel 718 produced by EBM. [11] The effect of thermal history on as-built parts is being investigated in separate work, and is known to be important to precipitate formation in laser melted Inconel 718. [12] The impact of variation in material properties with geometry and location was noted, and all builds presented in this paper were produced with the geometry shown in Figure 2 for horizontal specimens and a standard vertical test for the vertical tests in order to ensure comparable thermal histories. The texture of EBM produced Inconel 718 has been shown in previous work to orient columnar grains with the (100) plane oriented in the build direction. [6] [7] 


\section{Results and Discussion}

\section{Process Development}

For the electron beam melting process, beam current and velocity can be manually controlled in the ranges described previously. However, this does not represent the current state of practice for complex parts for which the systems are known. When inputs are controlled manually, the component will overheat at various locations, swelling will occur, and the build will not complete successfully. Therefore, Arcam has developed a complex processing algorithm in which processing parameters are varied based on component geometry. Because the algorithms are not accessible to the normal user, actual values would not be scientifically relevant for the work described. Figure 1 shows the influence of processing parameters on geometrical accuracy.
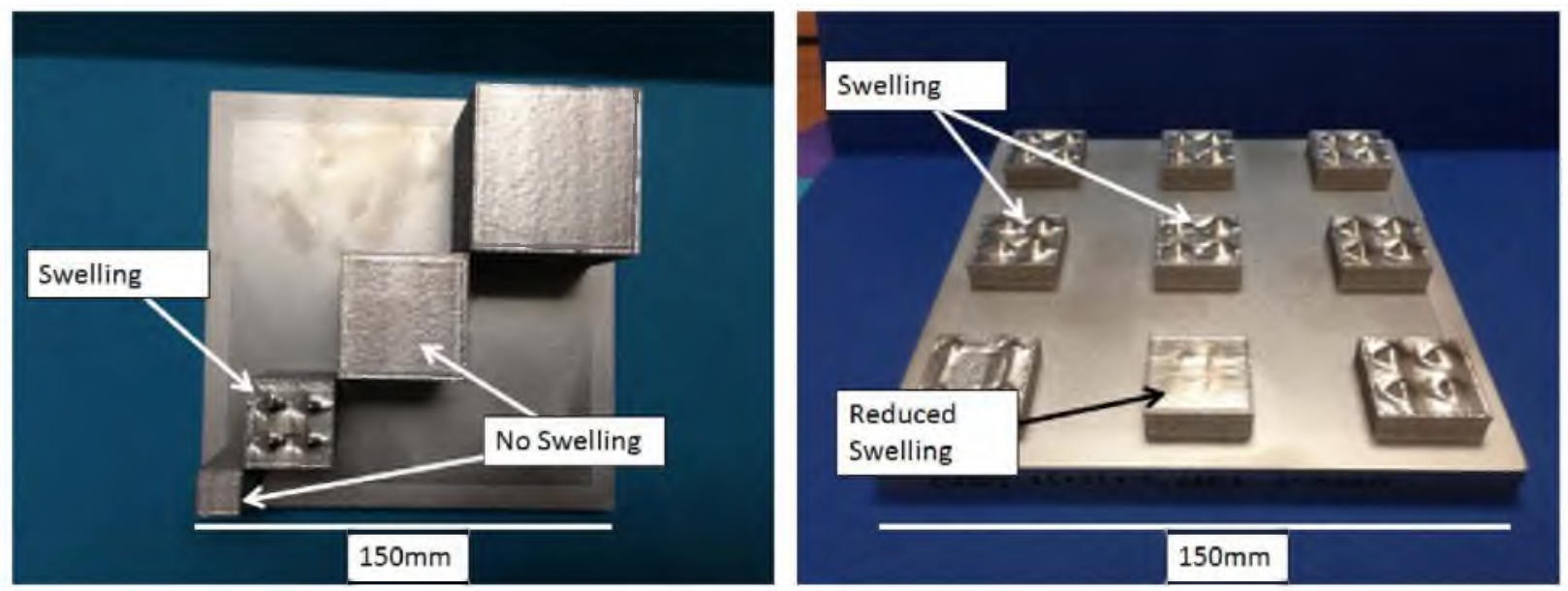

Figure 1. (Left) Test to demonstrate the ability of the Arcam system to make large parts and small parts within the same build. Parts were oriented to ensure that each melt was unaffected by the other melt features (not melted by measuring a combined scan line length). (Right) Test matrix to test the effect of turning point parameters.

The results in Figure 1 (Left) are particularly interesting; swelling can occur for beam passes in medium-sized parts, while not occurring for smaller and larger parts. Various parameters were tested to reduce this effect, where one parameter (the turning point function) was then studied in Figure 1 (Right). The turning point function was determined to be responsible for swelling reduction in the smallest part of Figure 1 (Left), but was not set properly to correct for mediumsized parts. The importance of this study shows that secondary process parameters (such as the turning point function) can only go so far in correcting the primary relationship between speed and current. The mechanism for the swelling of EBM parts is unstudied, but similar phenomena have been noted in welding [13] [14] [15] [16]. Swelling phenomena in welding are related to surface tension effects on the weld pool. Differences in weld pool geometry and temperature during overheat are likely factors contributing to the swelling in additive manufacturing. 

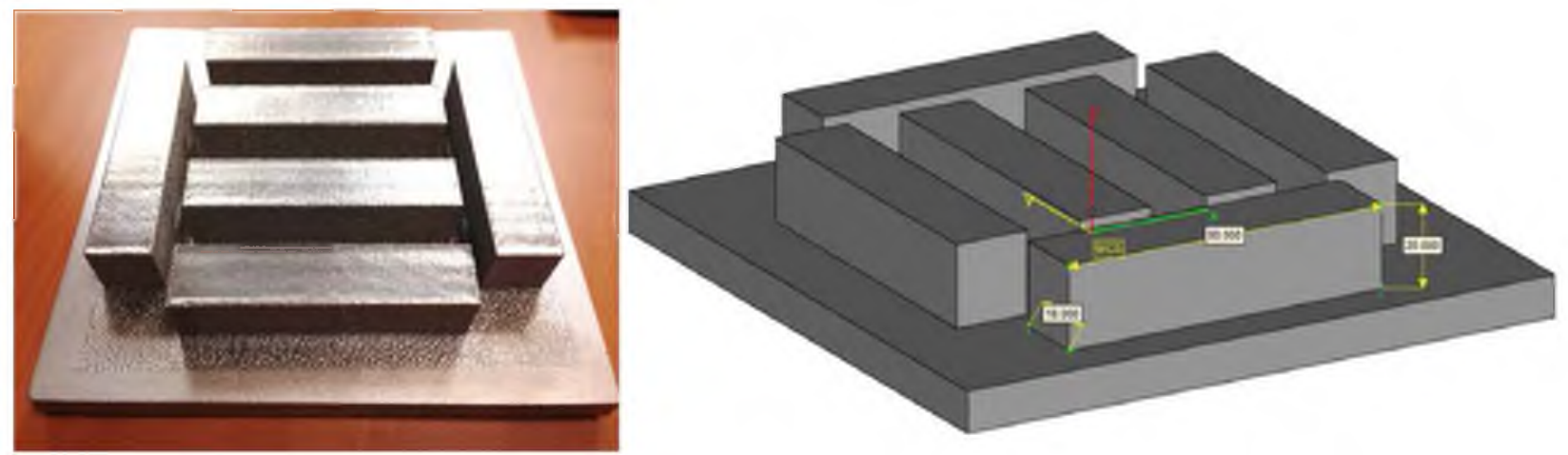

Figure 2. Horizontal Inconel 718 samples post-build, adhered to stainless steel substrate.

Process parameters were optimized to eliminate swelling and yield geometrically accurate parts as shown in Figure 2 by changing the relationship of speed and power to input less energy. When modifying process parameters, there is a balance between eliminating process induced porosity and overheating the build material. If the melt current supplied is not sufficient, incomplete melting or particle ejection may occur, leading to process induced porosity. Particle ejection during melting can be noted by visual observation through the machine window. Ejection has been noted to correlate powder bed temperature, where an average substrate temperature of $975 \pm 25^{\circ} \mathrm{C}$ tended to minimize particle ejection. For temperatures $<950^{\circ} \mathrm{C}$, ejection increases as powder bed temperature decreases. Process induced porosity can be identified by crack-like, non-spherical pore shapes as shown by light optical microscopy (LOM) Figure 3. The shape of process induced porosity may be due to either lack-of-fusion or shrinkage.

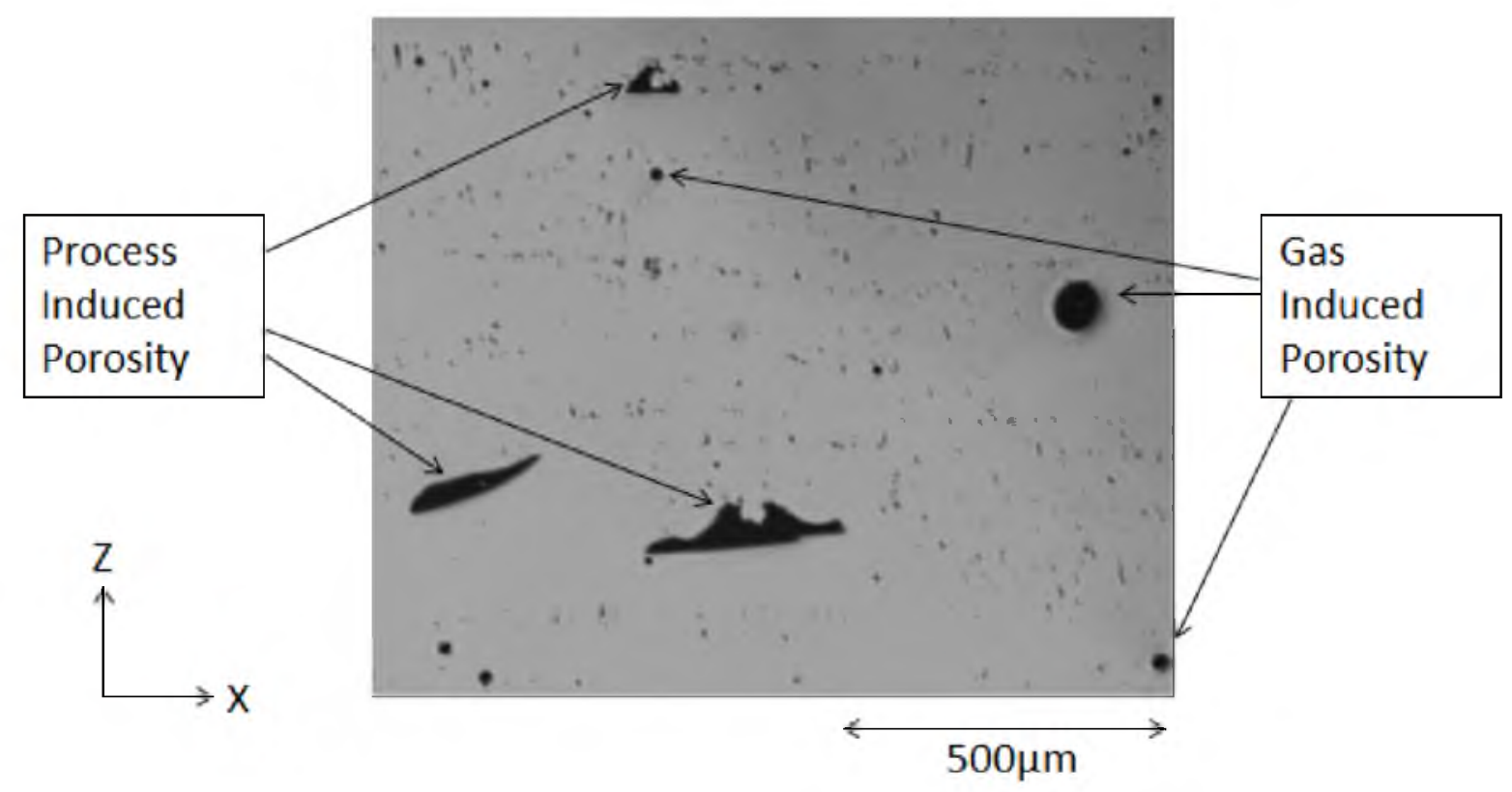

Figure 3. Process induced porosity vs. gas induced porosity for the GA - Vertical sample, LOM 50x. XZ plane, parallel to build direction. 
Figure 3 also contains spherical pores identified in the part. These pores are typically smaller than process induced porosity and are likely gas induced porosity. Because the process is performed under vacuum, it is anticipated that these pores must be inherent in the starting powder material. Other small, non-spherical imperfections in Figure 3 are precipitate phases that make LOM difficult to use to look at porosity. SEM was performed to better analyze the porosity.

\section{Variation of Powder Processing}

Gas induced porosity formed in this manner is formed from gas that is entrapped in the melt pool as it solidifies. In the EBM process, the source of this gas is considered to be entrapped Argon from the gas atomization (GA) or rotary atomization (RA) process. Previous laser AM studies have noted that using plasma rotating electrode process (PREP) powder eliminates the presence of gas induced porosity. [1] [5]

Powder samples were taken from three different batches of powder, each from a different supplier: GA, RA, and PREP. The powder samples were sieved and the distribution of sizes is given in Table 1. SEM and optical images shown in Figure 4 were taken to characterize the shape, quality, and internal porosity of the powders. After samples were melted by EBM, SEM images were taken of polished specimens. The results of the EBM produced material are compared to original powder porosity in Figure 5. It was demonstrated in this work that porosity in GA and RA powders translated to entrapped porosity in melted material. This was an interesting result, as even though the EBM process takes place in a vacuum, the pressure gradient is not enough to outgas entrapped gases from the melt pool during melting. Specifically, solidification happens so quickly in the EBM process that there is not enough residence time in the molten state for the gas to escape. PREP powder was shown to greatly reduce (nearly eliminate) part porosity.

Powder recycling effects are a concern, as powder from the EBM process is recycled after numerous thermal cycles, sintering, and mechanical blasting during powder recovery. Used PREP powder is shown in Figure 6 after $\sim 420$ hours. Compared to the original powder before use, there are minor surface defects and evidence of mechanical deformation of powder as shown in Figure 6(d). The effect of powder cycling is important to continue to study, and should be done for smaller time steps and by quantifying powder characteristics at these steps. 
(a)

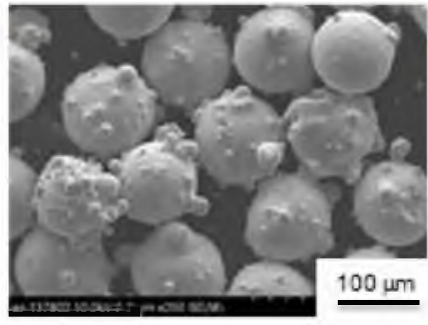

(d)

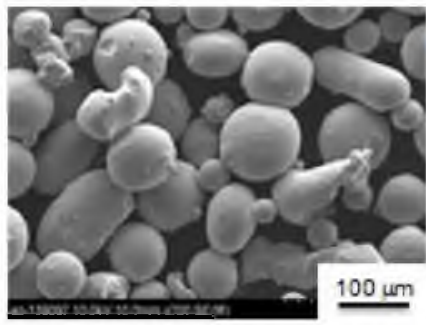

(g)

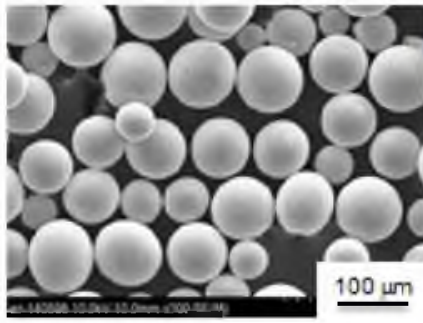

(b)

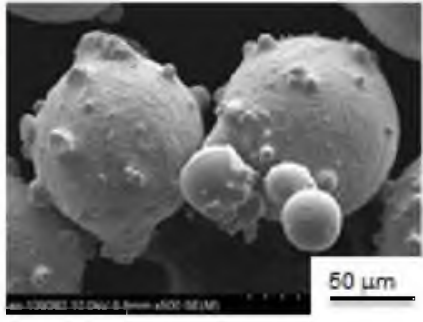

(e)

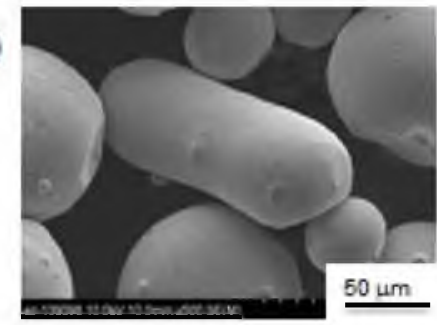

(h)

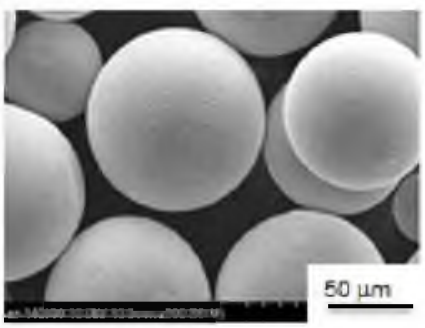

(c)

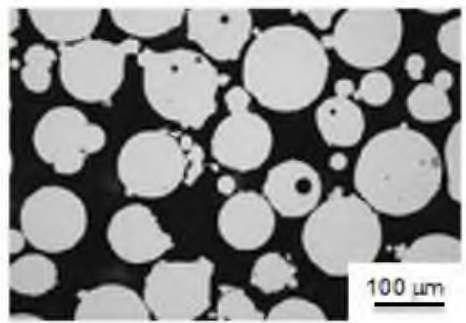

(f)

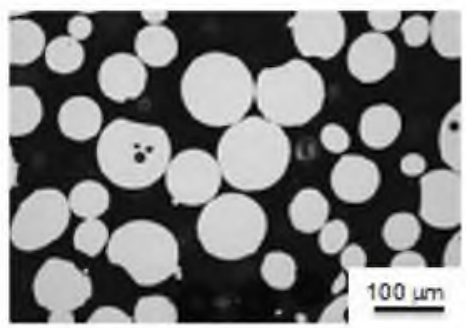

(i)

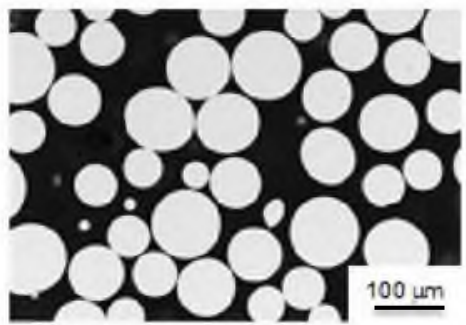

Figure 4. Comparison of powder quality before use: (a) SEM 250x of GA, (b) SEM 500x of GA, (c) LOM of GA, (d) SEM 200x of RA, (e) SEM 500x of RA, (f) LOM of RA, (g) SEM 200x of PREP, (h) SEM 500x of PREP, (i) LOM of PREP.

(a)

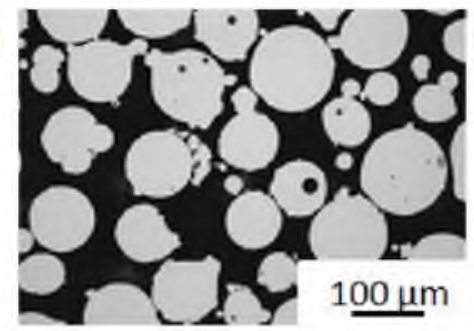

(b)

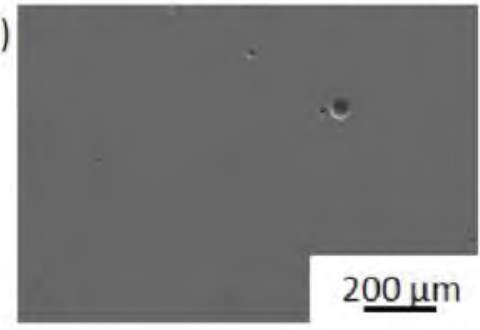

(c)

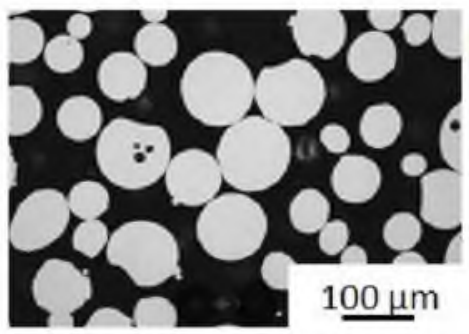

(d)

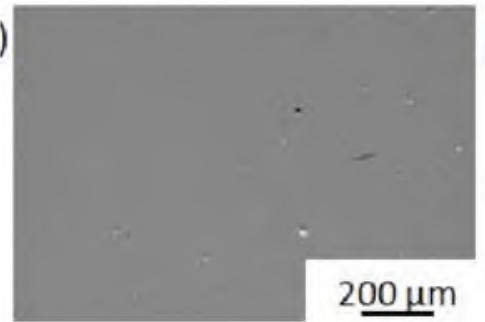

(e)

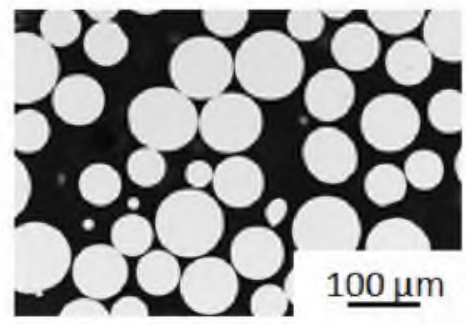

(f)

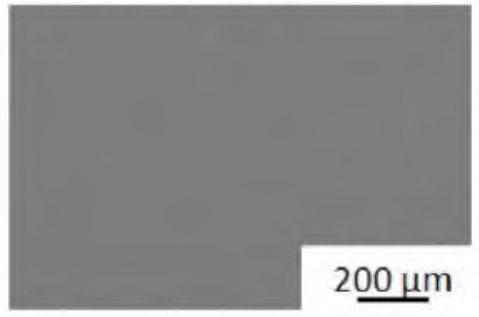

Figure 5. SEM images with enhanced contrast, parallel to build direction (XZ plane) taken from bottom of sample. (a) LOM of GA, (b) SEM of GA, (c) LOM of RA, (d) SEM of RA, (e) LOM of PREP, and (f) SEM of PREP. 
(a)

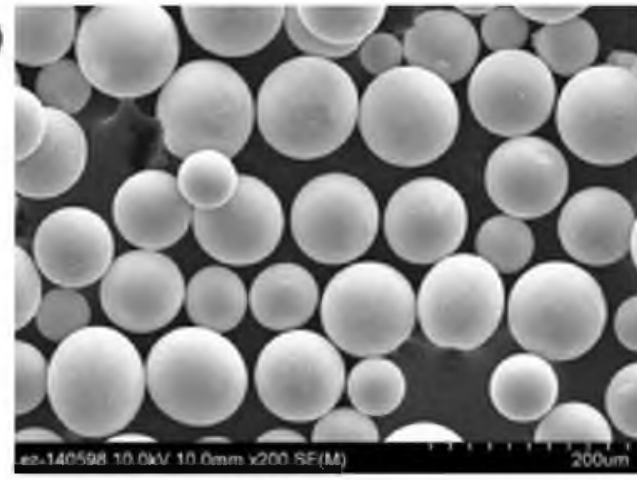

(c)

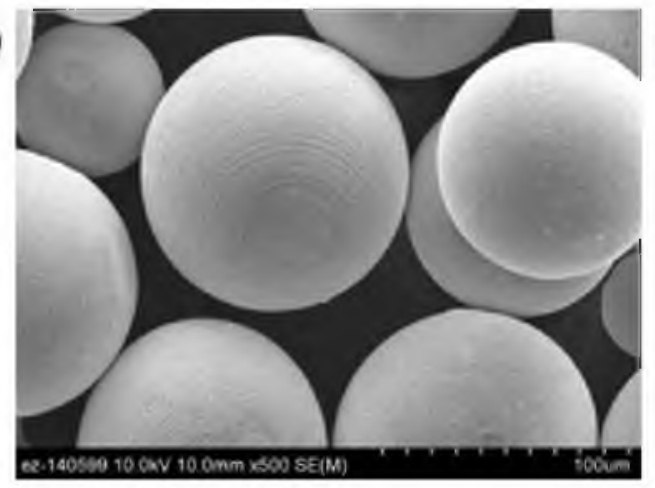

(b)

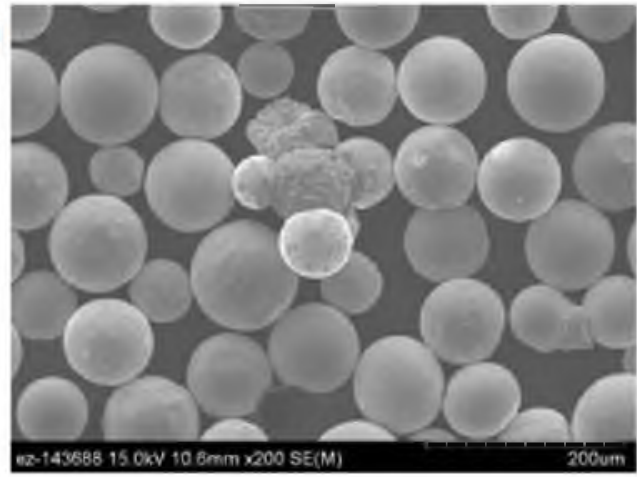

(d)

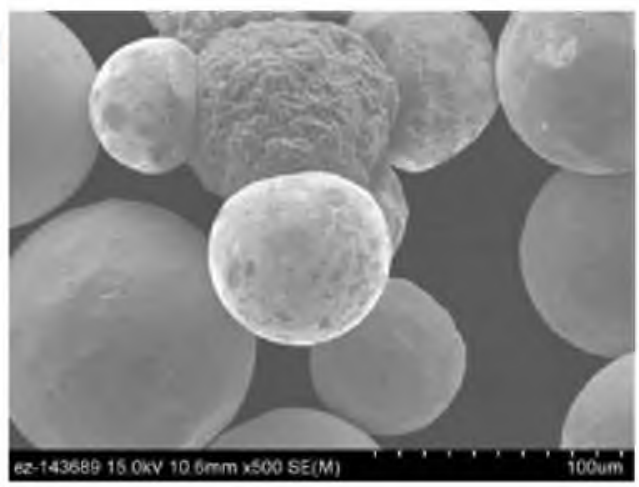

Figure 6. (a) New PREP powder at 200X, (b) used PREP powder after $\sim 420$ hours at 200X, (c) New PREP powder at 500X, and (d) used PREP powder after $\sim 420$ hours at 500X.

\section{Relationship between processing parameters, microstructure, and mechanical properties}

The microstructure and mechanical properties of EBM samples were studied. The effect of layer thickness, cool down rate, powder quality, and orientation on mechanical properties was studied. The PREP fast cool horizontal sample was polished and electro-etched to reveal the nature of the grain structure as shown in Figure 7. XRD was performed on the horizontal PREP sample as shown in Figure 8. The columnar grain structure and high orientation of the 100 in the XY plane are in agreement with previous work on Inconel 718 fabricated by EBM. [8] The results of the mechanical tests are shown in Table 2, alongside comparative data from the literature. The reported standard deviations were taken from the number of samples run for each case or study (2-6 samples per case). Representative stress-strain curves from individual tests are shown in Figure 9. 

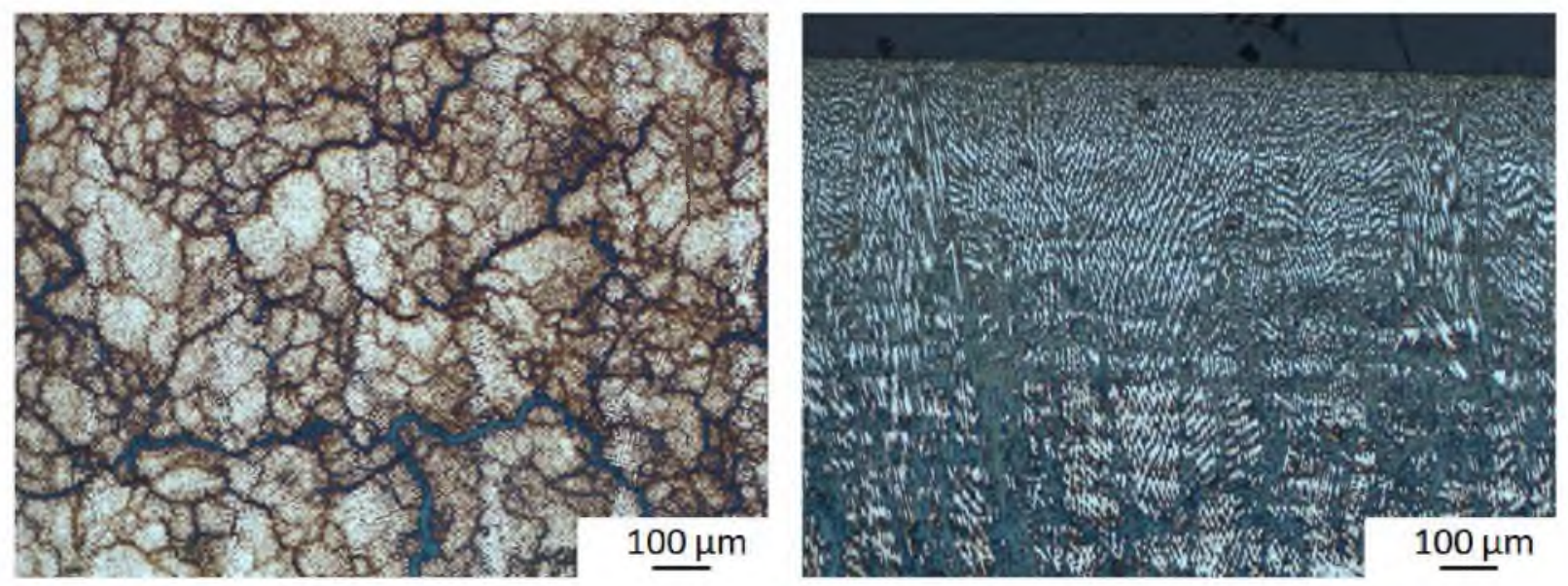

Figure 7. (Left) LOM of etched XY plane, perpendicular to build direction and (Right) LOM of etched XZ plane near the top of the sample, parallel to build direction. Both images from the PREP fast cool sample.

(a)
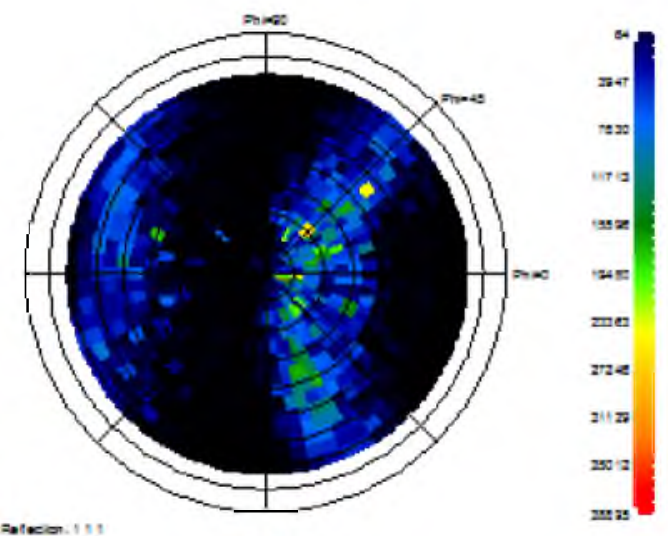

(c)

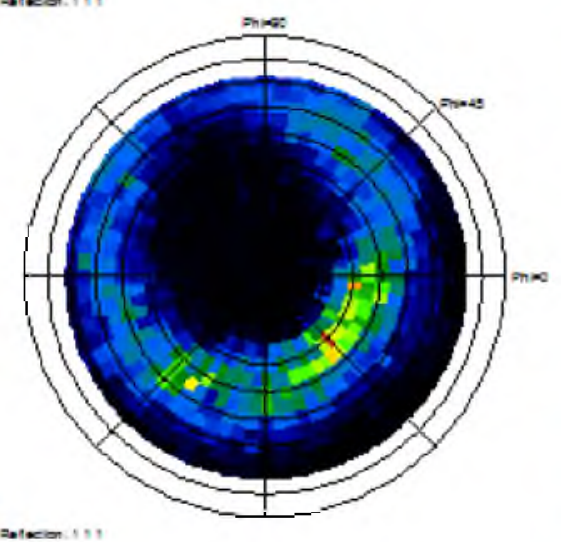

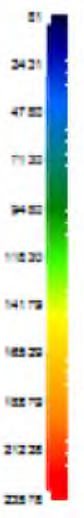

(b)
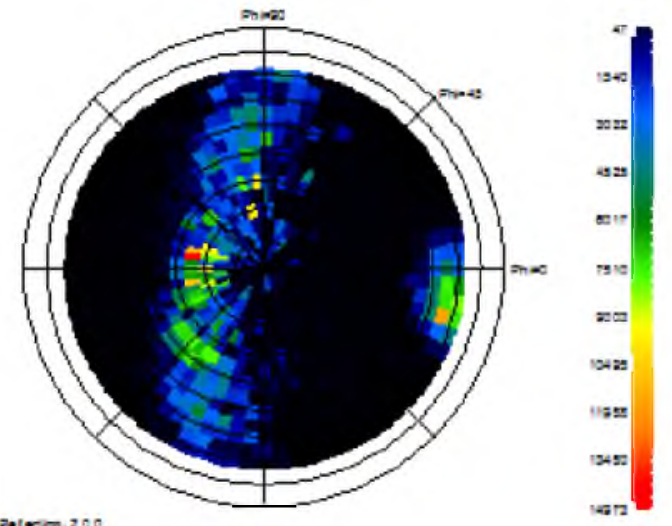

(d)

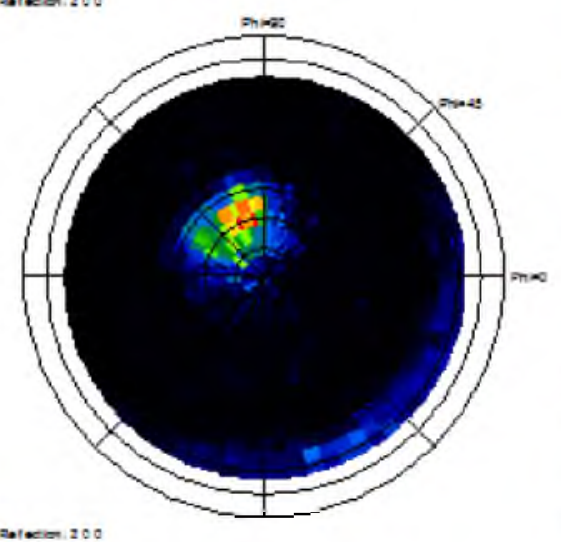

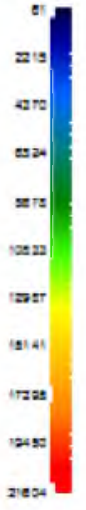

Figure 8. Pole figures from the PREP fast cool sample of (a) the (111) reflection from the $X Z$ face, (b) the (200) reflection from the $\mathrm{XZ}$ face, (c) the (111) reflection from the $\mathrm{XY}$ face, and (d) the (200) reflection from the XY face. 


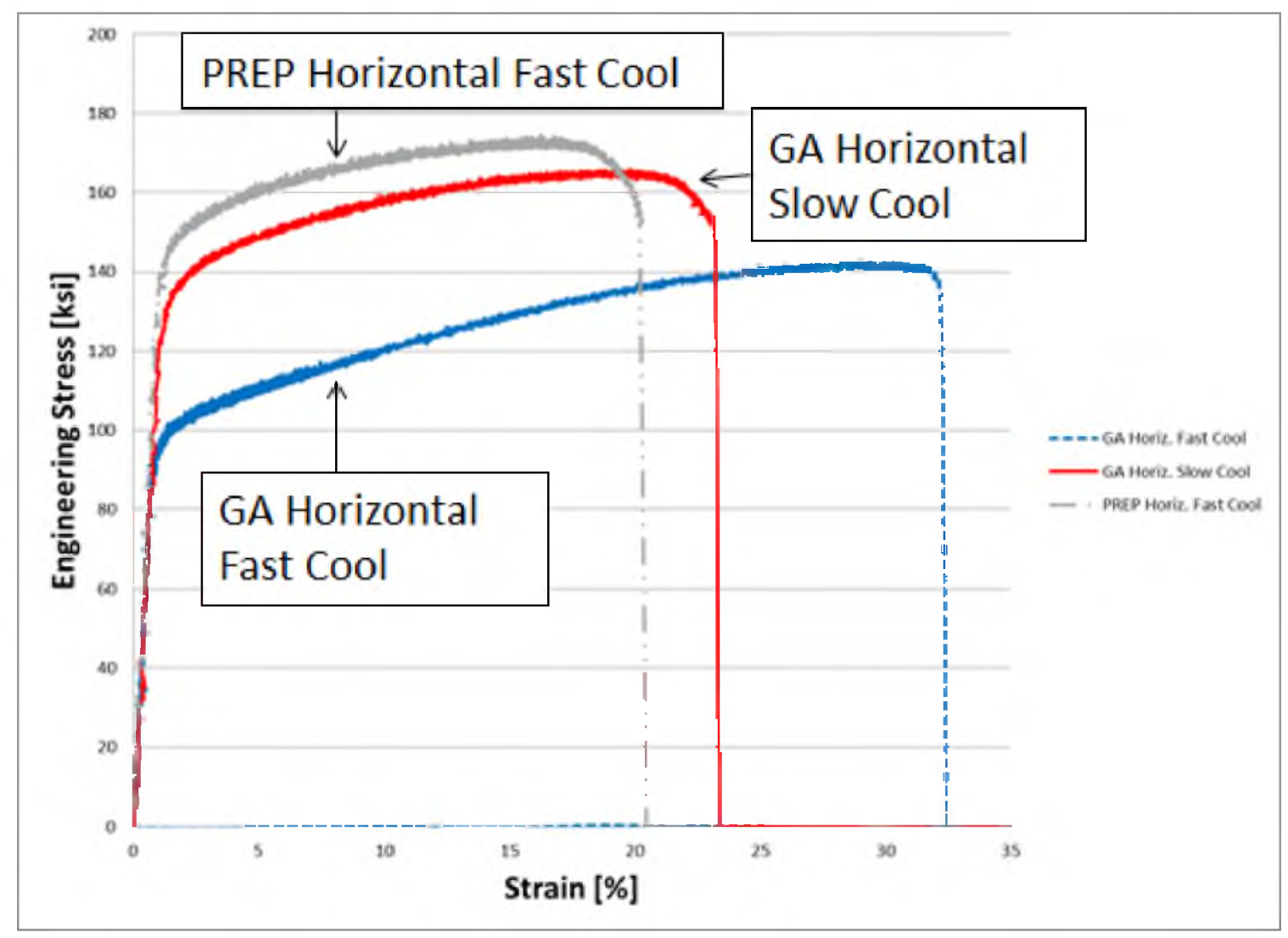

Figure 9. Representative stress vs. strain results from tensile tests.

The elongation values of as-built specimens compare favorably to the properties of wrought material, but fall short of the UTS of wrought bar material. The UTS of wrought sheet material is close to some of the slow cooled samples. In general, a slow cool (vacuum cool) gives better strength and reduced elongation when compared to the fast cool (helium convection cool), which has better ductility. There appears to be little effect of layer thickness (50 vs. 70 micron) in RA powder or orientation (vertical vs. horizontal) in GA powder. PREP powder displays more variation in orientation, with the horizontal specimens performing better in strength and ductility. Process induced porosity had little effect on UTS in the vertical GA samples, but drastically reduced elongation. The effect of powder quality and gas induced porosity on tensile properties seems to be low, especially compared to the much more significant impact of process induced porosity (as shown by the two separate GA vertical builds). The PREP samples displayed the best tensile properties for fast cooled samples, but were very similar in properties to slow cooled RA powder samples.

When comparing the GA horizontal fast cool and slow cool builds, it was expected that fast cooled builds would produce high elongation and lower strength. This was not observed for the PREP fast cool sample as shown in Figure 9. The thermal histories for these builds were considered as measured from the substrate in Figure 10. It becomes evident why the PREP fast 
cool sample did not behave as predicted; even though the geometry of the sample was controlled, some process condition changed to increase the hold time and decrease the hold temperature. This change was determined to be a software change from 3.2 to 4.1 , with a set of new parameters that needed optimization. The new 4.1 software can actually achieve a much more constant hold temperature, although that was not demonstrated in this experiment. By increasing the hold time by about two hours and decreasing the temperature below the solvus for many of the precipitates for Inconel 718, one can rationalize that the phases formed in the PREP fast cool mat have been very different from the GA fast cool. The hold times, hold temperatures, and software versions for other builds are given in Table 3. The effect of the hold time and hold temperature may be used with a combination of TTT and CCT diagrams to help rationalize the microstructure. [17]

Table 2. Tensile test results for as-built material, presented alongside other results for as-built material from various sources. ( ${ }^{*}$ GA sample was run at a cold powder bed temperature, and experienced process induced porosity)

\begin{tabular}{|c|c|c|c|c|c|c|c|}
\hline Study & Process & Powder & Orientation & $\begin{array}{l}\text { Layer } \\
\text { Thickness } \\
{[\mu \mathrm{m}]}\end{array}$ & $\begin{array}{l}\text { UTS } \\
\text { [MPa] }\end{array}$ & $\begin{array}{l}\mathrm{YS}(0.2 \%) \\
{[\mathrm{MPa}]}\end{array}$ & $\begin{array}{l}\text { Elongation } \\
{[\%]}\end{array}$ \\
\hline GA - fast cool & EBM & GA & Horizontal & 50 & $942 \pm 61$ & $590 \pm 40$ & $34 \pm 2.6$ \\
\hline GA - slow cool & EBM & GA & Horizontal & 50 & $1108 \pm 50$ & $869 \pm 32$ & $22 \pm 1.8$ \\
\hline GA - fast cool* & EBM & GA & Vertical & 50 & $1003 \pm 21$ & $887 \pm 16$ & $5.4 \pm 1.7$ \\
\hline GA - fast cool & EBM & GA & Vertical & 50 & $1082 \pm 10$ & $822 \pm 12$ & $20 \pm 0.6$ \\
\hline RA - slow cool & EBM & RA & Horizontal & 70 & $1142 \pm 41$ & $957 \pm 30$ & $19 \pm 4.6$ \\
\hline RA - slow cool & EBM & RA & Horizontal & 50 & $1186 \pm 34$ & $974 \pm 20$ & $20 \pm 1.3$ \\
\hline PREP - fast cool & EBM & PREP & Horizontal & 50 & $1186 \pm 19$ & $967 \pm 28$ & $20 \pm 1.4$ \\
\hline PREP - fast cool & EBM & PREP & Vertical & 50 & $1069 \pm 44$ & $632 \pm 88$ & $17 \pm 2.4$ \\
\hline ASTM $\quad$ F3055-14 & - & - & Horizontal & - & 980 & 635 & 27 \\
\hline Stress Relieved [18] & - & - & Vertical & - & 920 & 600 & 27 \\
\hline ASTM $\quad$ F3055-14 & - & - & Horizontal & - & 1240 & 940 & 12 \\
\hline $\begin{array}{l}\text { HIP+STA+Age and } \\
\text { STA+Age [18] }\end{array}$ & - & - & Vertical & - & 1240 & 920 & 12 \\
\hline Unocic 2014 [11] & EBM & RA & Vertical & Unknown & 1207 & 669 & 21 \\
\hline Bampton 2013 [19] & EBM & Unknown & Vertical & Unknown & 776.81 & 689.48 & 3.8 \\
\hline Strondl 2011 [7] & EBM & PREP & Horizontal & Unknown & $1060 \pm 26$ & $822 \pm 25$ & 22 \\
\hline Strondl 2011 [7] & EBM & PREP & Vertical & Unknown & $929 \pm 20$ & $744 \pm 44$ & 5.5 \\
\hline Qi 2009 [1] & LNSM & PREP & Thin Wall & Unknown & 904 & 552 & 16.2 \\
\hline Zhao 2008 [5] & LRF & GA & NR & Unknown & 845 & 590 & 11 \\
\hline Wrought - Bar [20] & - & - & - & - & 1430 & 1190 & 21 \\
\hline $\begin{array}{l}\text { Wrought - Sheet } \\
{[20]}\end{array}$ & - & - & - & - & 1280 & 1050 & 22 \\
\hline
\end{tabular}


EBM samples compare favorably to previous work. Laser Engineered Net Shaping (LENS) samples and Laser Net Shaped Manufactured (LNSM) are both freeform laser process that do not utilize a powder bed, but spray powder into a molten pool, to produce material. As-fabricated material from these processes has lower elongation and lower UTS than EBM materials. Based on the results presented here, slow cooled PREP samples would display the best tensile properties and could potentially meet and exceed wrought-sheet properties. Additionally, RA slow cool samples produced slightly higher strength but lower elongation than GA samples. This could be an effect of porosity, or it could be slight differences in thermal build history. Though samples were run with the similar parameters, changes in operating conditions could have led to different thermal profiles. A comparison of the build volume temperature and hold times should be performed to reach more definite conclusions on the effect of powder size.

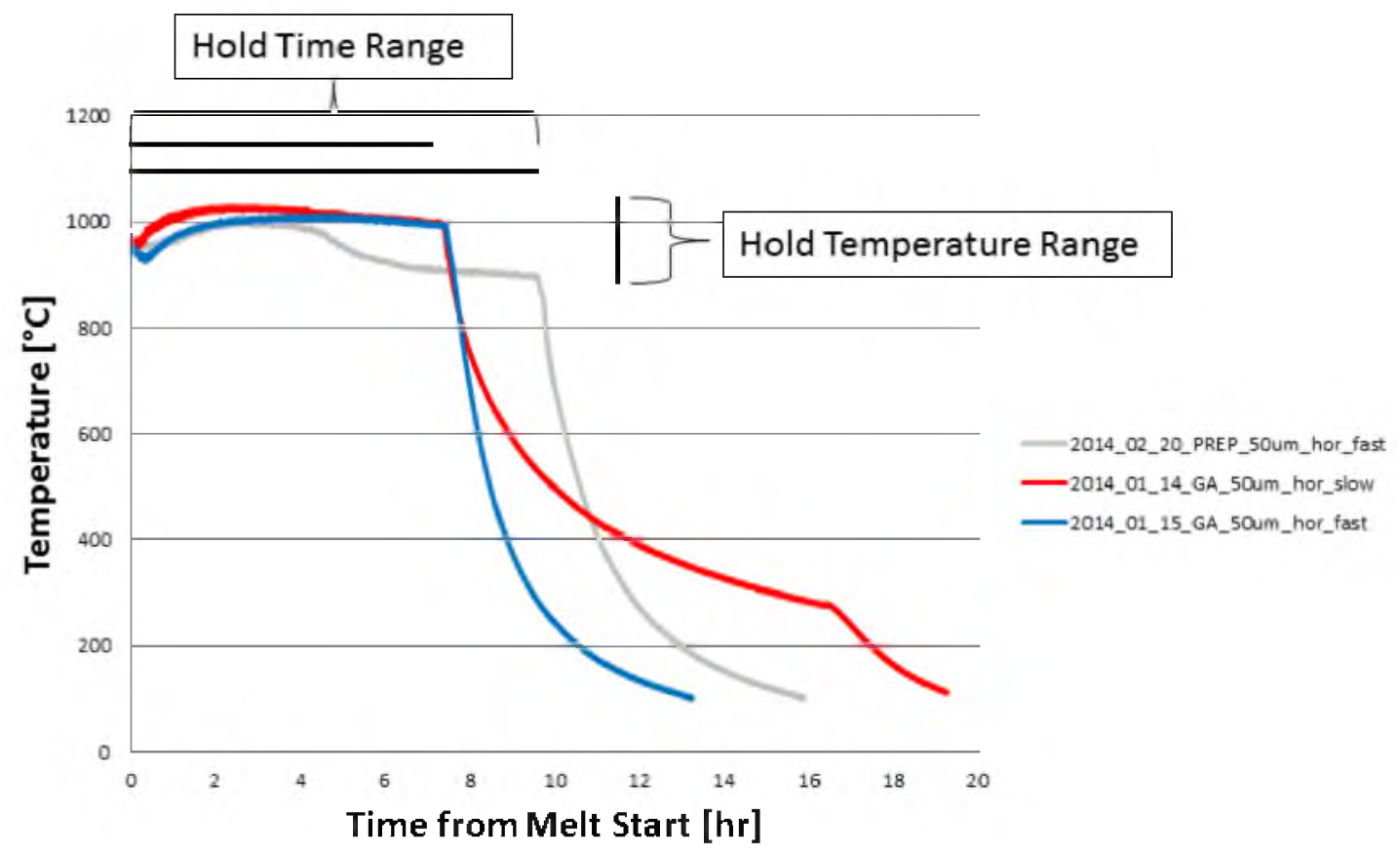

Figure 10. Thermal histories of selected builds as measured from underneath the substrate.

Table 3. Thermal histories of the melt process as measured from the substrate thermocouple.

\begin{tabular}{|l|l|l|l|l|l|}
\hline Study & Orientation & $\begin{array}{l}\text { Layer } \\
\text { Thickness }[\mu \mathrm{m}]\end{array}$ & $\begin{array}{l}\text { Software } \\
\text { Version }\end{array}$ & $\begin{array}{l}\text { Hold Time } \\
{[\mathrm{hr}]}\end{array}$ & $\begin{array}{l}\text { Hold Temperature } \\
{\left[{ }^{\circ} \mathrm{C}\right]}\end{array}$ \\
\hline GA - fast cool & Horizontal & 50 & 3.2 & 7.44 & $924-1010$ \\
\hline GA - slow cool & Horizontal & 50 & 3.2 & 7.49 & $948-1029$ \\
\hline GA - fast cool* & Vertical & 50 & 3.2 & 19.75 & $877-999$ \\
\hline GA - fast cool & Vertical & 50 & 3.2 & - & - \\
\hline RA - slow cool & Horizontal & 70 & 3.2 & 6.36 & $910-1004$ \\
\hline RA - slow cool & Horizontal & 50 & 3.2 & 7.66 & $907-989$ \\
\hline PREP - fast cool & Horizontal & 50 & 4.1 & 9.63 & $886-1004$ \\
\hline PREP - fast cool & Vertical & 50 & 4.1 & 42.84 & $818-982$ \\
\hline
\end{tabular}




\section{Conclusion}

The procedure for achieving quality EBM parts was outlined and the various steps were discussed. Process parameters were fine tuned to achieve geometrically accurate parts, and the dependency of swelling on an appropriate relationship between current and velocity was noted. Powder production method has a notable effect on powder quality, which was shown to affect the amount of gas induced porosity in EBM parts. PREP powder parts displayed negligible porosity, with GA and RA powder parts both displaying gas induced porosity. Tensile samples were tested for a variety of conditions and it was noted that:

- The majority of tensile results exhibited better strength and ductility than as-built LRF and LNSM parts

- The majority of tensile results are similar to some previous EBM studies (Unocic et al. and horizontal results from Strondl et al.) and are an improvement over other results (Bampton et al. and vertical results from Strondl et al.)

- The majority of the samples tested meet the ASTM F3055 standard for stress relieved UTS and YS, as well as the elongation for stress relieved + solution treat + aged

- PREP powder helps greatly reduce porosity, but makes little impact on tensile properties

- The effect of hold time and hold temperature are important for as-built properties, and should be reported with any future as-built property tests

Inconel 718 as-built via EBM exhibits columnar grains, high orientation, and variations in tensile properties that can be explained based on thermal history. Future work should explore postprocessing using HIP and heat treatments, which is commonly used on conventional Inconel 718. [21] HIP is used to close pores in cast Inconel 718 [22], and has been explored in other work on AM parts. Future work to better understand, and control, phase formation during the process should also be done. While PREP powder may not make a measureable impact on tensile properties, the impact on fatigue, creep, and crack growth may be more noticeable and should be studied. It is important to note the importance of improving the properties of as-built parts for two reasons: (1) if as-built parts are to be put directly into service, then porosity and as-built mechanical properties matter and (2) potential variation in solid-state phase transformations may affect the time and temperature needed to affectively solution treat the EBM material.

\section{Acknowledgements}

Research sponsored by the U.S. Department of Energy, Office of Energy Efficiency and Renewable Energy, Advanced Manufacturing Office, under contract DE-AC05-00OR22725 with UT-Battelle, LLC. This research was also supported by fellowship funding received from the U.S. Department of Energy, Office of Nuclear Energy, Nuclear Energy University Programs. Notice: This manuscript has been authored by UT-Battelle, LLC, under Contract No. DE-AC0500OR22725 with the U.S. Department of Energy. The United States Government retains and the 
publisher, by accepting the article for publication, acknowledges that the United States Government retains a non-exclusive, paid-up, irrevocable, world-wide license to publish or reproduce the published form of this manuscript, or allow others to do so, for United States Government purposes.

\section{Works Cited}

[1] H. Qi, M. Azer and A. Ritter, "Studies of Standard Heat Treatment Effects on Microstructure and Mechanical Properties of Laser Net Shape Manufactured INCONEL 718," Metallurgical and Materials Transactions A, vol. 40A (2009), 2410-2422.

[2] K. N. Amato, S. M. Gaytan, L. E. Murr, E. Martinez, P. W. Shindo, J. Hernandez, S. Collins and F. Medina, "Microstructures and mechanical behavior of Inconel 718 fabricated by selective laser melting," Acta Materiala, vol. 60, no. 5 (2012), 2229-2239.

[3] Z. Wang, K. Guan, M. Gao, X. Li, X. Chen and X. Zeng, "The microstructure and mechanical properties of deposited-IN718 by selective laser melting," Journal of Alloys and Compounds, vol. 513 (2012), 518-523.

[4] Q. Jia and D. Gu, "Selective laser melting additive manufacturing of Inconel 718 superalloy parts: Densification, microstructure and properties," Journal of Alloys and Compounds, vol. 585 (2014), 713-721.

[5] X. Zhao, J. Chen, X. Lin and W. Huang, "Study on microstructure and mechanical properties of laser rapid forming Inconel 718," Materials Science and Engineering A, vol. 478 (2008), 119124.

[6] A. Strondl, R. Fischer, G. Frommeyer and A. Schneider, "Investigations of MX and gamma'/gamma" precipitates in the nickel-based superalloy 718 produced by electron beam melting," Materials Science and Engineering A, vol. 480 (2008), 138-147.

[7] A. Strondl, M. Palm, J. Gnauk and G. Frommeyer, "Microstructure and mechanical properties of nickel based superalloy IN718 produced by rapid prototyping with electron beam melting (EBM)," Materials Science and Technology, vol. 27, no. 5 (2011), 876-883.

[8] A. Strondl, S. Milenkovic, A. Schneider, U. Klement and G. Frommeyer, "Effect of Processing on Microstructure and Physical Properties of Three Nickel-Based Superalloys with Different Hardening Mechanisms," Advanced Engineering Materials, vol. 14, no. 7 (2012), 427438.

[9] ASTM International, "E8/E8M - 11: Standard Testing Methods for Tension Testing of Metallic Materials," ASTM International (2012) West Conshohocken, PA.

[10] J. Mireles, C. Terrazas, F. Medina and R. Wicker, "Automatic Feedback Control in Electron Beam Melting Using Infrared Tomography," Solid Freefrom Fabrication Symposium (2013), Austin, TX.

[11] K. A. Unocic, L. M. Kolbus, R. R. Dehoff, S. N. Dryepondt and B. A. Pint, "HighTemperature Performance of N07718 Processed by Additive Manufacturing," NACE Corrosion (2014), San Antonio, TX. 
[12] K. T. Makiewicz, "Development of Simultaneous Transformation Kinetics Microstructure Model with Application to Laser Metal Deposited Ti-6Al-4V and Alloy 718" (M.S. Thesis, Ohio State University, 2013).

[13] A. Arora, G. G. Roy and T. Debroy, "Unusual wavy weld pool boundary from dimensional analysis," Scripta Materialia, vol. 60 (2009), 68-71.

[14] U. Gratzke, P. D. Kapadia, J. Dowden, J. Kroos and G. Simon, "Theoretical approach to the humping pheonomenon in welding processes," J. Phys. D: Appl. Phys., vol. 25 (1992), 16401647.

[15] T. C. Nguyen, D. C. Weckman, D. A. Johnson and H. W. Kerr, "The humping phenomenon during high speed gas metal arc welding," Science and Technology of Welding and Joining, vol. 10, no. 4 (2005), 447-459.

[16] J. I. Achebo, "Complex Behavior of Forces Influencing Molten Weld Metal Flow based on Static Force Balance Theory," Physics Procedia, vol. 23 (2012), 317-324.

[17] W. J. Sames, K. A. Unocic, R. R. Dehoff, T. Lolla and S. S. Babu, "Thermal Effects on Microstructural Heterogeneity of Inconel 718 Materials Fabricated by Electron Beam Melting," Journal of Materials Research (2014, accepted).

[18] ASTM International, "F3055 - 14: Standard Specification for Additive Manufacturing Nickel Alloy(UNS N07718) with Powder Bed Fusion," ASTM International (2014), West Conshohocken, PA.

[19] C. Bampton, J. Wooten and B. Hayes, "Additive Manufactuing by Electron Beam Melting (EBM) of Alloy 718," Material Science \& Technology (2013), Montreal, Canada.

[20] M. Bauccio, ASM Metals Reference Book, Third Edition (Materials Park, OH: ASM International, 1993).

[21] ASM International, "Nickel-Base Superalloys," Heat Treater's Guide: Practices and Procedures for Nonferrous Alloys (Materials Park, OH:ASM International, 1996) 41-58.

[22] J. F. Radavich, "The Physical Metallurgy of Cast and Wrought Alloy 718," Superalloy 718 Metallurgy and Applications (TMS, 1989). 